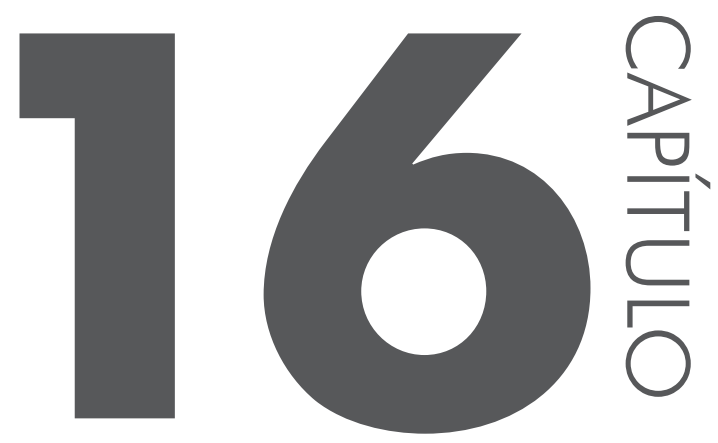

\title{
MICROFLOTAÇÃO DE APATITA COM ÓLEOS DA POLPA E DA CASTANHA DE MACAÚBA
}

Canuele Adamiane Tiago Pachêco ${ }^{1}$ André Carlos Silva ${ }^{1}$

Elenice Maria Schons Silva ${ }^{1}$ Tércio Willian Pereira Rocha ${ }^{1}$

Agradecimentos: Às agências de fomento CNPq, CAPES, FAPEG e FUNAPE pelo suporte financeiro que possibilitou esta pesquisa e, adicionalmente, à Anglo American Fosfato e à Universidade Federal de Goiás.

Resumo: A apatita é a principal fonte do fosfato usado como insumo na fabricação de fertilizantes agrícolas; portanto, estudos que buscam alternativas para o melhor aproveitamento deste minério são de suma importância em um

1 Unidade Acadêmica Especial de Engenharia, Universidade Federal de Goiás - Regional Catalão, Catalão, Brasil.

E-mail de contato: canuele@hotmail.com 
país essencialmente agropecuário como o Brasil. Durante o seu beneficiamento, os ácidos graxos atuam como agente coletor na etapa de flotação, assim, torna-se fundamental a busca por sistema de reagentes que aumentem a eficiência neste processo. Neste sentido a macaúba (Acrocomia aculeata) é um fruto que desperta interesse por apresentar grandes concentrações de componentes oleaginosos tanto na polpa $(43,8 \%)$ quanto na castanha $(36,2 \%)$. As diferenças na composição de ácidos graxos sugerem comportamentos distintos quando usados como coletores na flotação. O presente trabalho procurou demonstrar, através de ensaios de microflotação em tubo de Hallimond, o potencial de utilização dos óleos de macaúba na flotação de apatita. Os testes foram realizados com 1,0g de apatita de alta pureza, numa granulometria de $104 \mu \mathrm{m}$, nos $\mathrm{pHs} 8,9$ e 10 variando as concentrações do coletor em 2,$5 ; 5,0 ; 7,5$ e 10,0mg/L. Os resultados mostraram uma recuperação maior, em todas as concentrações testadas, para o óleo da polpa quando comparada com o óleo da castanha de macaúba.

Palavras-chave: Flotação. Ácidos graxos. Macaúba. Apatita.

Abstract: The apatite is the main source of phosphate used as input in the manufacture of industrial fertilizers, so studies that seek alternatives to the best use of this ore is very important in an essentially agricultural country like Brazil. During its processing, the fatty acids act as collector agent in the flotation step thus becomes essential to search for reagent system that would improve efficiency in this process. In this sense, the macaúba (Acrocomia aculeata) is a fruit that arouses interest for present high concentrations of fatty acids. The differences in fatty acid composition suggest different behavior when used as collectors in the flotation of minerals. the present study sought to demonstrate, through microflotation testing Hallimond tube, the potential use of macaúba oils in the flotation of apatite. The tests were performed with $1.0 \mathrm{~g}$ of high purity apatite, with a particle size of $104 \mu \mathrm{m}$ at $\mathrm{pH} 8,9$ e 10 varying concentrations of the collector at 2.5, 5.0, 7.5 and $10.0 \mathrm{mg} / \mathrm{L}$. The results showed a better floatability at all concentrations tested for pulp oil compared with macaúba's nut oil.

Keywords: Flotation. Fatty acids. Macaúba. Apatite.

\section{INTRODUC̣ÃO}

A busca por processos sustentáveis é crescente em diferentes ramos de produção, tanto para adequação aos padrões estabelecidos pela legislação ambiental quanto para redução de custos. $\mathrm{Na}$ mineração, encontrar reagentes que apresentem alta eficiência e seletividade para aplicação na concentração de minérios fosfatados é um dos grandes desafios em um país essencialmente agropecuário como o Brasil e dependente da importação deste produto de países como Marrocos e China. 
O grupo da apatita $\left(\mathrm{Ca}_{5}(\mathrm{Cl}, \mathrm{F}, \mathrm{OH})\left(\mathrm{PO}_{4}\right)_{3}\right)$ representa a maioria dos minérios de fósforo das rochas fosfatadas e os depósitos formados por esses minérios sílico-carbonatados possuem uma complexa mineralogia, contendo impurezas que influenciam sua recuperação nas usinas de beneficiamento. O processo de separação mais eficiente empregado para concentração de minerais do grupo da apatita é a flotação e diversos são os produtos químicos utilizados neste processo. Dentre eles, os coletores são substâncias inseridas na mistura aquosa, que recobrem a superfície das partículas do mineral e aumentam a afinidade destes com as bolhas de ar, fazendo que o mecanismo de captura dos minerais pelo fluxo de ar seja mais eficiente. Nas mineradoras que exploram o fosfato, os sistemas de coletores comumente empregados no processo de flotação são oleaginosos (compostos por um conjunto de ácidos graxos), podendo ser naturais ou sintéticos. Os ácidos graxos são particularmente relevantes porque são responsáveis pela concentração de importantes minérios brasileiros.

A baixa seletividade obtida nos processos de separação do fosfato geralmente é atribuída às similaridades existentes nas propriedades eletrocinéticas, solubilidade e química de superfície destes com os minerais de ganga presentes nas jazidas. Para Albuquerque (2010) os metais alcalinos terrosos semelhantes presentes na estrutura cristalina destes minerais contribuem para a adsorção não seletiva dos agentes coletores. Neste contexto, a escolha do sistema de reagentes de flotação é fator determinante na eficiência deste processo.

A flotação é uma técnica que explora as condições de hidrofilicidade e hidrofobicidade das partículas (BALTAR, 2008). Considerando que as apatitas são classificadas como minerais levemente solúveis e se caracterizam por apresentar solubilidade menor do que os minerais altamente solúveis, mas superior à grande maioria dos óxidos e silicatos, variações aparentemente pequenas nas suas propriedades superficiais podem interferir no seu comportamento. Assim, os coletores podem atuar neste processo extremamente sensível de maneira a garantir uma maior adsorção dos minerais de interesse.

$\mathrm{Na}$ flotação, é a composição do mineral que determina os mecanismos de adsorção do coletor, podendo ser físicos ou químicos. No caso das apatitas, o tipo de interação varia com o pH e distingue-se pelo ponto isoelétrico, que se dá aproximadamente em $\mathrm{pH}$ 9. Portanto, uma interação coletor/mineral mais efetiva é atingida quando ocorre a quimissorção, promovida em potencial zeta é negativo.

A busca por seletividade em sistemas de flotação envolvendo minerais levemente solúveis tem sido motivo de diversas pesquisas. Estudos fundamentais, bem como testes em escala de laboratório e piloto, têm sido realizados com diferentes tipos de minérios e sistemas de reagentes, objetivando subsidiar tal separação.

Neste sentido, os óleos vegetais, ricos em ácidos graxos, são objeto de investigação em relação ao seu potencial como coletores, no intuito de, dentre outros, 
buscarem reagentes alternativos aos comumente utilizados, que possuem custo elevado e acarretam na degradação do ambiente. Dentre estes estudos cabe ressaltar o trabalho realizado por Costa (2012), que analisou o uso de óleos vegetais amazônicos na flotação de minérios fosfáticos. Os resultados obtidos no trabalho indicam que é grande a possibilidade de utilização de óleos vegetais amazônicos como coletores na flotação dessa classe de minérios.

No que tange à seletividade na flotação de minérios silicocarbonatados, pesquisas com o óleo de jojoba foram realizadas por Santos e Oliveira (2012) constatando a eficiência do óleo como coletor alternativo na separação de apatita e calcita. Um fruto que desperta interesse é a macaúba (Acrocomia aculeata), visto o seu reconhecido potencial oleaginoso e a sua multiplicidade de uso industrial. Pachêco et al. (2014) compararam a recuperação do óleo da polpa da macaúba saponificado com o reagente industrial Flotigam 5806 em ensaios com tubo de Hallimond usando apatita com alto teor de pureza em uma granulometria de $-65+80 \#(-210+177 \mu \mathrm{m})$ em $\mathrm{pH} 9$ e obtiveram resultados satisfatórios, nos quais a recuperação deste óleo apresentou valores semelhantes ao coletor aplicado industrialmente.

A macaúba é uma palmácea de ocorrência natural em toda a zona tropical da América Latina. Sua exploração econômica ocorre tanto em sistemas extrativistas quanto em cultivos racionais, com produtos e usos diversos como farmacológico, nutracêutico, madeireiro, artesanal, forrageiro, alimentício e combustível (REMAPE, 2014). Segundo Nobre et al.(2014), esta palmeira apresenta um rendimento médio em óleo de 4 toneladas por hectare, bem superior ao rendimento das oleaginosas mais comumente utilizadas, como a soja, a mamona e o girassol, que apresentam produtividade média de $1 \mathrm{t} / \mathrm{ha}$. Estima-se que sua produtividade de óleo se aproxima à da palma africana (Elaeis guineensis), cerca de cinco toneladas de óleo por hectare. Esta é a cultura com maior produtividade de óleo por ha cultivado e também a que contribui com a maior parcela do óleo vegetal produzido em nível mundial (REMAPE, 2014).

Tendo em vista o alto potencial oleico da macaúba e a expansão do mercado consumidor do seu óleo para diversas finalidades, a palmeira da macaúba pode ser cultivada com viabilidade econômica em diferentes sistemas de produção. Estes sistemas de cultivo têm sido amplamente estudados pela Rede Macaúba de Pesquisa (REMAPE), desenvolvida pela Universidade Federal de Viçosa. Desta forma, a macaúba se caracteriza como uma espécie com qualidades importantes do ponto de vista natural, ecológico e principalmente socioeconômico.

Sabe-se hoje que todas as partes da macaúba, que é uma frutífera, têm utilidades. A Figura 1 apresenta a diferenciação de cada fração da macaúba. A extração de óleo vegetal é possível em duas das partes do fruto: polpa (mesocarpo) e castanha. Há também a produção de coprodutos de alto valor agregado, como 
os resíduos de polpa e da amêndoa após a prensagem e o endocarpo, que podem ser utilizados para nutrição animal e produção de carvão vegetal, respectivamente (REMAPE, 2014).

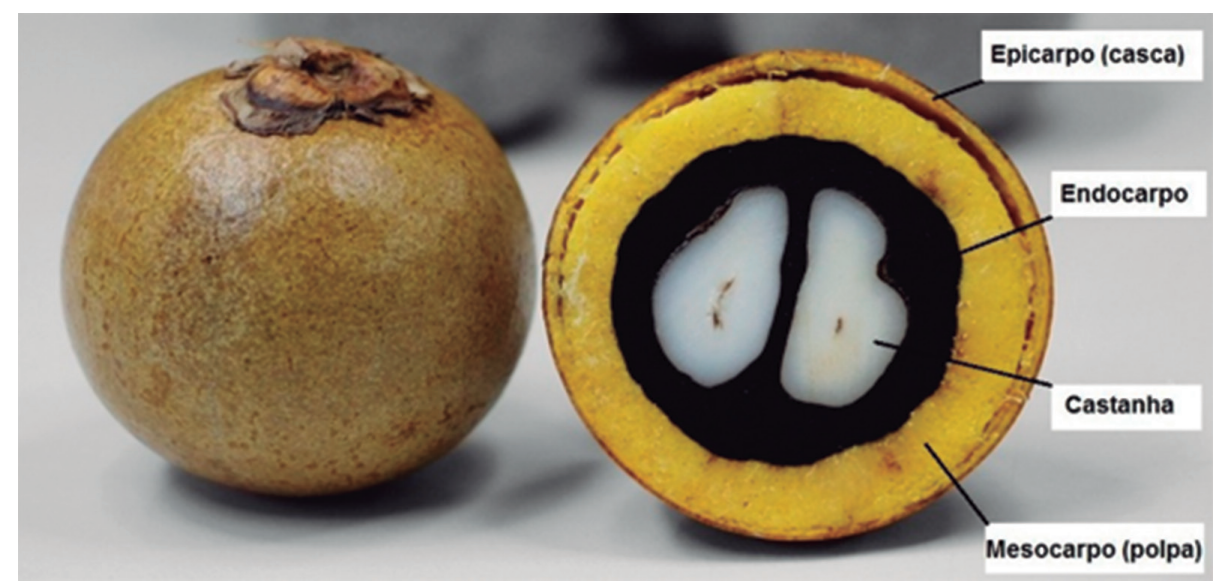

Figura 1. Partes da macaúba. Fonte: adaptada de Paulohilst, 2015.

A macaúba é um fruto oleaginoso que possui uma grande quantidade de ácidos graxos. Oliveira et al. (2009), em seu trabalho de caracterização físico-química da macaúba, constataram que o fruto é rico em lipídeos, correspondendo a $21,04 \%$ de sua composição. O estudo compara os resultados com outros trabalhos e indica que a Macaúba se assemelha a outras fontes vegetais oleaginosas como o pequi $(33,4 \%)$, a soja $(20 \%)$ e a azeitona $(18,5 \%)$.

Zuppa (2001) realizou a análise de óleos vegetais de frutos do Cerrado, conduzindo testes de caracterização por Cromatografia Gasosa de Alta Resolução. Desta pesquisa observou-se que a amêndoa e a polpa da macaúba apresentaram alta viabilidade de extração de óleo. O perfil da composição de ácidos graxos descrito pela autora mostra que para a polpa da macaúba a concentração mais elevada é o ácido oleico (58,7\%), seguido de ácido palmítico (19,7\%). Já para a castanha as maiores concentrações são de ácido láurico $(39,7 \%)$ e ácido oleico $(25,8 \%)$.

A Figura 2 apresenta o perfil completo de ácidos graxos para cada uma das partes. As diferenças apresentadas na composição dos ácidos graxos dos óleos extraídos da polpa e da castanha da Macaúba sugerem comportamentos distintos quando usados na flotação.

A macaúba é um fruto que apresenta vantagens sobre outras oleaginosas, principalmente com a relação à sua maior rentabilidade agrícola e à produção total de óleo. Portanto, é de fundamental importância estudos sobre novas aplicações dos produtos gerados pela exploração desta espécie. 


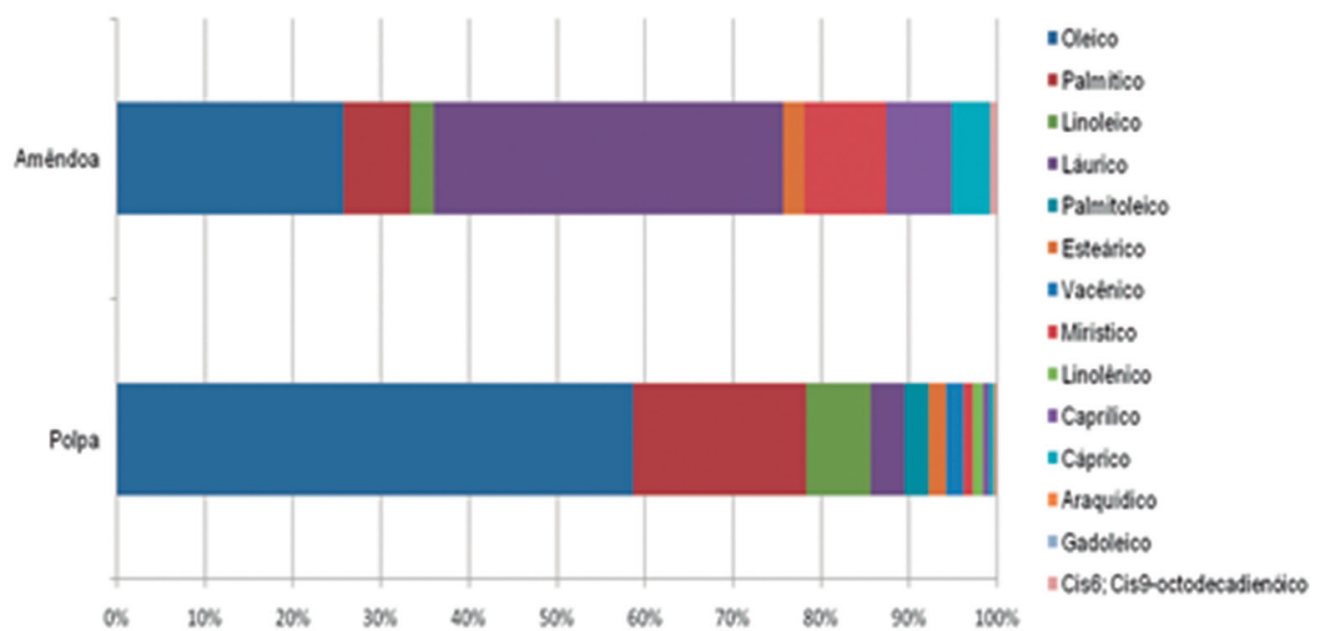

Figura 2. Composição (\%) em ácidos graxos da polpa e amêndoa da macaúba. Fonte: adaptada de Zuppa (2001).

Nesse contexto, este trabalho procurou testar estes dois óleos como uma nova alternativa de reagentes, aplicando-os no processo de separação da apatita no intuito de comparar seu potencial para ser utilizado na flotação com um coletor aplicado industrialmente.

\section{MATERIAIS E MÉTODOS}

O mineral de apatita usado neste trabalho foi adquirido na sua forma natural em uma empresa de mineração e submetido, em laboratório, aos procedimentos de moagem em moinho de bolas, peneiramento via úmido com peneirador suspenso para classificação em faixas granulométricas, filtragem no filtro de vácuo e secagem em estufa com temperatura média de $60{ }^{\circ} \mathrm{C}$ para seu posterior armazenamento em recipientes devidamente identificados pela faixa granulométrica. A Figura 3 apresenta uma imagem microscopia óptica do mineral, na granulometria usada nos testes.

Amostras deste mineral foram enviadas para análise química em uma mineradora da cidade de Catalão, utilizando-se do equipamento Espectrômetro de Fluorescência de Raios - X Panalytical, modelo AXIOX MAX série DY n5001, o qual fornece a composição do mineral adquirido e utilizado nos testes de flotação. Os óleos da polpa da macaúba (OPM) e da castanha (OCM) foram adquiridos diretamente com os produtores, a Unidade Beneficiamento Coco Macaúba (UBCM), por meio da Associação Riacho D’antas Macaúba, com sede em Montes Claros - Minas Gerais. Para serem usados como coletores, os óleos foram submetidos à hidrólise alcalina, também chamada de saponificação. Esse procedimento permitiu torná-los solúveis em água, facilitando a atuação destes como coletor. 


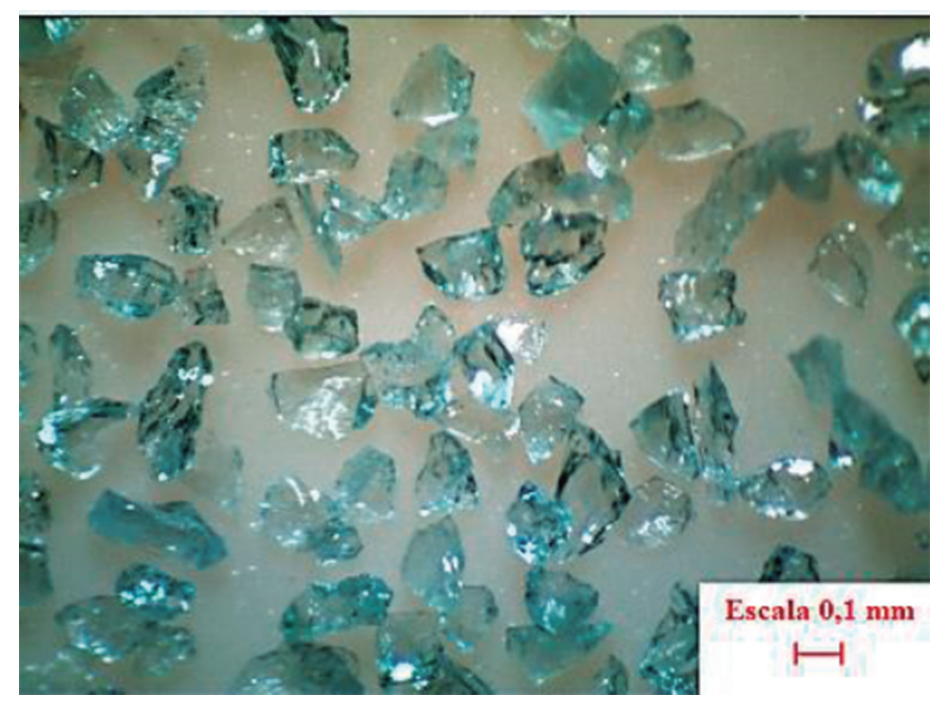

Figura 3. Apatita após cominuição e peneiramento $-100+150 \#(-150+106 \mu \mathrm{m})$.

O procedimento de saponificação dos óleos de macaúba (polpa e castanha) foi realizado utilizando-se hidróxido de sódio a $10 \%$. Neste procedimento, foram adicionados 5,0g de óleo a 20,0g de água, dispondo a mistura em um agitador magnético. Ligada à agitação, adicionou-se 7,5 mL de hidróxido de sódio a 10\% para saponificar a solução. Retornando o recipiente para a balança, adicionou-se água até que a solução atingisse 100,0g. Por fim, o conjunto novamente foi disposto no agitador magnético para homogeneização.

Para efeito de comparação da eficiência destes óleos com um reagente usado industrialmente, foi escolhido o Flotigam 5806, produzido pela Clariant, que passou pelo mesmo procedimento de saponificação descrito para os óleos da macaúba. O tubo de Hallimond foi o equipamento usado neste trabalho, uma vez que constitui um método de fácil determinação da hidrofobicidade ou hidrofilicidade dos minerais, definindo se o reagente empregado é eficaz na recuperação do mineral analisado. Os testes de microflotação foram realizados com amostras puras de apatita, numa granulometria de $-100+150 \#(-150+106 \mu \mathrm{m})$ e nos $\mathrm{pH} 8,9$ e 10, variando as concentrações dos coletores. Os testes foram realizados em triplicata, totalizando 108 testes.

O condicionamento foi realizado pelo período de 7 minutos de forma mais concentrada, isto é, colocou-se na parte final do tubo o mineral, uma quantidade de coletor que garanta a concentração final desejada variando em 2,5; 5,0; 7,5 e $10,0 \mathrm{mg} / \mathrm{L}$ e completou-se com água até o limite de $50 \mathrm{~mL}$ de solução para condicionamento. Chegando ao final do condicionamento, adicionou-se o restante da água necessária ao procedimento, chegando a uma solução com $320 \mathrm{~mL}$ para então iniciar-se a flotação com intervalos de duração de 1 minuto. 
Assim, para cada um dos óleos da macaúba (polpa e castanha) e Flotigam 5806 variou-se a concentração em quatro valores diferentes de acordo com a quantidade de solução saponificada adicionada. A Tabela 1 resume as condições comuns a todos os testes de microflotação com os coletores:

Tabela 1. Condições dos testes de microflotação de apatita

\begin{tabular}{cc}
\hline Condições & Valores \\
\hline Vazão de ar & $40 \mathrm{~cm}^{3} / \mathrm{min}$ \\
$\mathrm{pH}$ & 8,9 e 10 \\
Faixa granulométrica & $-100+150 \#(-150+106 \mu \mathrm{m})$ \\
Massa do mineral & $1 \mathrm{~g}$ \\
Condicionamento & 7 minutos \\
Flotação & 1 minuto \\
Concentrações & 2,$5 ; 5,0 ; 7,5$ e $10,0 \mathrm{~mL}$ \\
\hline
\end{tabular}

Os ensaios de arraste hidráulico em tubo de Hallimond revelaram um baixo índice de transporte hidrodinâmico, ou seja, o carreamento de partículas pelo fluxo ascendente gerado com a passagem do ar. Os testes apresentaram um arraste de aproximadamente $0,7 \%$ para a vazão $40 \mathrm{~cm}^{3} / \mathrm{min}$. Dessa maneira, os dados de microflotação serão apresentados desconsiderando valores de arraste. A recuperação da apatita foi calculada a partir da relação entre a massa flotada e a massa total da amostra.

\section{RESULTADOS E DISCUSSÃO}

A análise de caracterização da amostra de apatita revelou a presença em pequenas quantidades de barita e ferro. Entretanto, as concentrações de $\mathrm{P}_{2} \mathrm{O}_{5}$ e CaO são elevadas, condizendo com uma amostra com alto grau de pureza. A Tabela 2 apresenta esses resultados.

Tabela 2. Análise de amostras de apatita após cominuição e classificação

\begin{tabular}{cccccccc}
\hline Óxido & $\mathrm{Nb}_{2} \mathrm{O}_{5}$ & $\mathrm{P}_{2} \mathrm{O}_{5}$ & $\mathrm{Fe}_{2} \mathrm{O}_{3}$ & $\mathrm{SiO}_{2}$ & $\mathrm{BaO}$ & $\mathrm{Al}_{2} \mathrm{O}_{3}$ & $\mathrm{CaO}$ \\
\hline$\%$ & - & 40,50 & 0,07 & 0,94 & 0,06 & 0,38 & 52,04 \\
\hline
\end{tabular}

Os resultados dos testes de microflotação são apresentados nas Figuras 4, 5 e 6. Quando comparado com o Flotigam 5806, o OPM obteve melhor recuperação (valores maiores que $90 \%$ ) do que o OCM quando usados como coletores 
na flotação de apatita. Para todas as concentrações dos coletores nota-se uma diferença significativa na recuperação do OCM, principalmente nas menores $(2,5$ e $5,0 \mathrm{mg} / \mathrm{L})$.

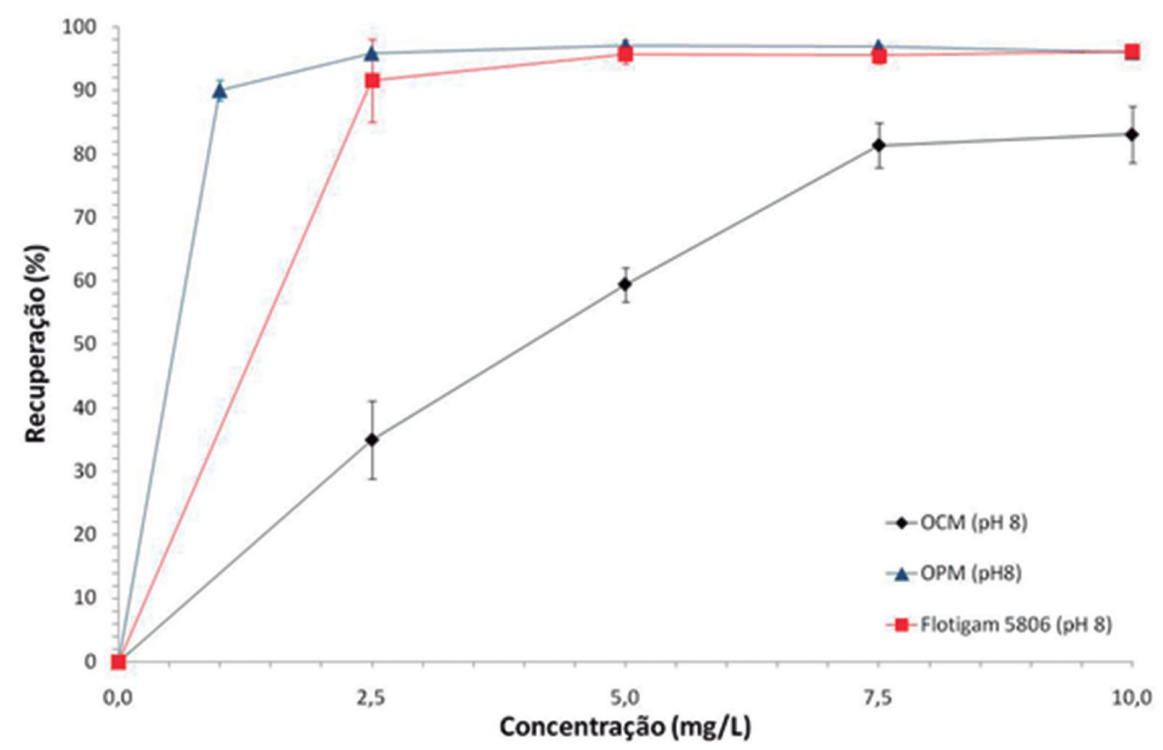

Figura 4. Variação da recuperação de apatita em função da concentração do óleo da polpa de macaúba saponificado (OPM), óleo da castanha de macaúba saponificado (OCM) e do Flotigam 5806 em pH 8.

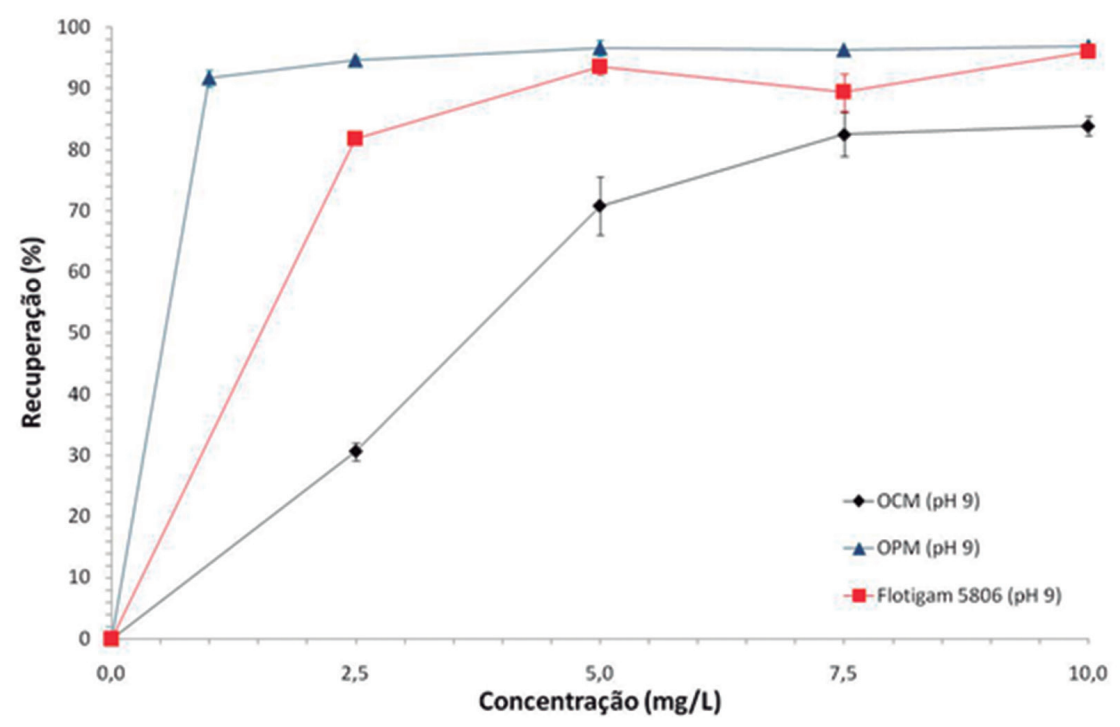

Figura 5. Variação da recuperação de apatita em função da concentração do óleo da polpa de macaúba saponificado (OPM), óleo da castanha de macaúba saponificado (OCM) e do Flotigam 5806 em pH 9. 


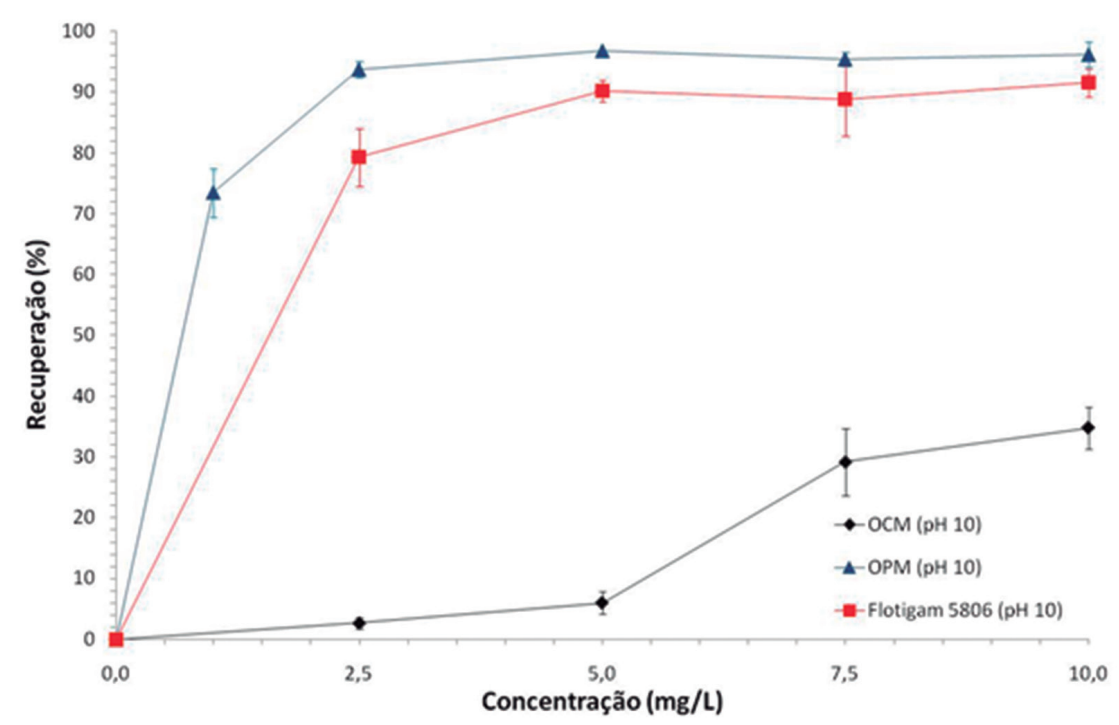

Figura 6. Variação da recuperação de apatita em função da concentração do óleo da polpa de macaúba saponificado (OPMS), óleo da castanha de macaúba saponificado (OCMS) e do Flotigam 5806 em pH 10.

Testes de microflotação em tubo de Hallimond com apatita pura, conduzidos por Brandão, Caires e Queiroz (1994) demonstraram que os ácidos graxos insaturados (linoleico, oleico e linolênico) tiveram desempenho superior em relação aos saturados. Considerando a distinção nas composições de ácidos graxos observadas para cada uma das partes do fruto apresentados na Figura 2 pode-se relacionar a diferença na eficiência de coleta obtida nos testes realizados ao teor de ácido oleico presente no óleo da polpa $(58,7 \%)$, comprovando seu maior potencial de uso como coletor na flotação, conforme apresentado nas figuras 4, 5 e 6. Nota-se também que mesmo com a variação do $\mathrm{pH}$ em 8,9 e 10 , a recuperação de apatita pelo coletor OPM não teve alterações significativas, diferentemente dos demais coletores (OCM e Flotigam 5806) para os quais a recuperação diminuiu com a elevação do $\mathrm{pH}$.

\section{CONCLUSÃO}

A capacidade de empregar óleos vegetais extraídos da macaúba na flotação vem de encontro a um dos grandes desafios da indústria de fosfato, que é desenvolver um sistema de reagentes mais seletivos e economicamente viáveis para concentração de minérios sílico-carbonatados. Considerando que o óleo da polpa da macaúba (polpa) atingiu resultados de recuperação expressivos e por necessitar dosagens baixas do coletor no processo de flotação da apatia, este pode ser considerado uma alternativa eficiente e acessível. 
Os testes de microflotação usando os óleos saponificados da macaúba (polpa e castanha) indicam que estes coletores podem atuar satisfatoriamente na flotação de apatita. No entanto, para o óleo da polpa da macaúba as condições de flotação se dariam com menores concentrações do reagente, visto que, a partir de 2,5mg/L, o coletor já apresenta resultados de recuperação expressivo. Enquanto que para o uso do óleo da castanha da macaúba a dosagem ideal seria a partir de 7,5mg/L para atingir resultados de microflotação de apatita desejados.

Considerando que o óleo da macaúba é um reagente natural e ocorre em cultivos extrativistas, seu uso na flotação contribuirá para a redução de impactos ambientais, sendo uma tecnologia economicamente competitiva, promovendo o desenvolvimento socioeconômico de muitas regiões, além de reduzir a dependência externa do país. Diante do exposto, a palmeira macaúba apresenta grande potencial para produção de óleo com aplicação sustentável na flotação de minerais fosfatados. A viabilização das potencialidades dessa espécie fortalece a economia e a agricultura familiar. Portanto, conclui-se que o óleo da polpa da macaúba, por necessitar de menores dosagens do coletor no processo de flotação da apatia, é uma alternativa eficiente e acessível. Salienta-se a necessidade de realização de outros testes, para verificar sua aplicabilidade em escala industrial, pois a viabilização de um reagente mais seletivo na flotação e de baixo custo é particularmente interessante para o Brasil, pois poderia acarretar um melhor aproveitamento econômico e consequente aumento da vida útil das minas ou até mesmo viabilizaria novos empreendimentos, o que levaria a uma redução da importação de fertilizantes fosfatados.

\section{REFERÊNCIAS}

ALBUQUERQUE, R. Alternativas de processo para concentração do minério fósforouranífero de Itataia. Tese(Doutorado) - Escola de Engenharia, Universidade Federal de Minas Gerais, Belo Horizonte, 2010.

BALTAR, C. A. M. Flotação no tratamento de minério. Recife: UFPE, 2008.

BRANDÃO, P. R. G.; CAIRES, L. G.; QUEIROZ, D. S. B.Vegetable lipid oil-based collectors in the flotation of apatite ores. Minerals Engineering, v. 7, n. 7, p. 917-925, 1994. COSTA, D. S. Uso de óleos vegetais amazônicos na flotação de minérios fosfáticos. Tese (Doutorado) - Escola de Engenharia, Universidade Federal de Minas Gerais, Belo Horizonte, 2012.

NOBRE, D. A. C.; TROGELLO, E.; BORGHETTI, R. A.; DAVID, A. M. S. S. Macaúba: palmeira de extração sustentável para biocombustível. Colloquium Agrariae, v. 10, n. 2, p. 92-105, jul.-dez. 2014.

OLIVEIRA, A. L. S.; TORRES, M. A.; FREIRE, S. J.; PEREIRA, T. B.; SANTOS, T. F.; SILVA, V. O.; AZEVÊDO, L. C. Caracterização físico-química da Macaúba (Acrocomia Aculeata Jacq. Lodd.) cultivada no sertão pernambucano. In: IV Congresso de Pesquisa e Inovação da Rede Norte e Nordeste de Educação Tecnológica, 2009. Belém, Brasil. 
PACHÊCO, C. A. T.; SILVA, A. C.; SILVA, E. M. S.; ALVES, B. E. Macaúba’s pulp oil as collector in apatite froth flotation. In: International Mineral Processing Symposium, 2014. Kusadasi, Turquia.

PAULOHILST. Agricultura é a nossa vida. 2015. Disponível em: <http://www.paulohilst. com/agricultura-eacute-a-nossa-vida.html>. Acesso em: 20 mar. 2015.

REMAPE. Rede Macaúba de Pesquisa. Mineração. Disponível em: <http://www. macauba.ufv.br/.> Acesso em: 20 mar. 2015.

SANTOS, E. P.; OLIVEIRA, J. F. Utilização de óleo de jojoba como coletor alternativo na flotação seletiva entre apatita e calcita. Rio de Janeiro: PEMM/COPPE/UFRJ, 2012. ZUPPA, T. Avaliação das potencialidades de plantas nativas e introduzidas no Cerrado na obtenção de óleos e gorduras vegetais. Dissertação (Mestrado) - Instituto de Química, Universidade Federal de Goiás, Goiânia, 2001. 